\title{
Yeast: the soul of beer's aroma-a review of flavour-active esters and higher alcohols produced by the brewing yeast
}

\author{
Eduardo J. Pires • José A. Teixeira • Tomás Brányik • \\ António A. Vicente
}

Received: 12 November 2013 /Revised: 11 December 2013 / Accepted: 11 December 2013 /Published online: 3 January 2014

(C) Springer-Verlag Berlin Heidelberg 2014

\begin{abstract}
Among the most important factors influencing beer quality is the presence of well-adjusted amounts of higher alcohols and esters. Thus, a heavy body of literature focuses on these substances and on the parameters influencing their production by the brewing yeast. Additionally, the complex metabolic pathways involved in their synthesis require special attention. More than a century of data, mainly in genetic and proteomic fields, has built up enough information to describe in detail each step in the pathway for the synthesis of higher alcohols and their esters, but there is still place for more. Higher alcohols are formed either by anabolism or catabolism (Ehrlich pathway) of amino acids. Esters are formed by enzymatic condensation of organic acids and alcohols. The current paper reviews the up-to-date knowledge in the pathways involving the synthesis of higher alcohols and esters by brewing yeasts. Fermentation parameters affecting yeast response during biosynthesis of these aromatic substances are also fully reviewed.
\end{abstract}

Keywords Higher alcohols $\cdot$ Fusel alcohols $\cdot$ Esters $\cdot$ Beer aroma $\cdot$ Brewing yeast $\cdot$ Saccharomyces spp

\section{Introduction}

Beer is one of the most pleasant beverages in the world, the final taste/aroma of which is the resultant sum of several

\footnotetext{
E. J. Pires $(\bowtie) \cdot$ J. A. Teixeira $\cdot$ A. A. Vicente

IBB - Institute for Biotechnology and Bioengineering, Centre for

Biological Engineering, Universidade do Minho, Campus de Gualtar,

4710-057 Braga, Portugal

e-mail: eduardojvc@gmail.com

T. Brányik

Department of Biotechnology, Institute of Chemical Technology

Prague, Technická 5, 16628 Prague 6, Czech Republic
}

hundreds of flavour-active compounds produced in the course of every step of brewing. However, the great majority of these substances are produced during the fermentation phase and consist of metabolic intermediates or by-products of the main living character of brewing - the yeast. Higher alcohols, esters and vicinal diketones (VDKs) are the key elements produced by yeast, which will ultimately determine the final quality of the beer. While higher alcohols and esters are desirable volatile constituents of a pleasant beer, VDKs are often considered as off-flavours. Together with these, yeast metabolism contributes with other three groups of chemical compounds: organic acids, sulphur compounds and aldehydes.

All flavour-active components in beer must be kept within certain limits; otherwise, a single compound or group of compounds may predominate and destroy the flavour balance. Furthermore, potent odourants like esters may act in synergy with other components affecting beer flavour in concentrations well below their threshold values (Meilgaard 1975a). However, each type of beer has its own prevailing aroma triggered either by the yeast strain (Nykanen and Nykanen 1977; Peddie 1990; Ramos-Jeunehomme et al. 1991; Rossouw et al. 2008) chosen or by parameters used during fermentation (Lodolo et al. 2008; Saerens et al. 2008a; Bravi et al. 2009; Verbelen et al. 2009; Blasco et al. 2011; Berner and Arneborg 2012; Dekoninck et al. 2012; Hiralal et al. 2013). For example, while only isoamyl acetate (banana-like aroma) concentrations are above the threshold level in most lager beers, ales normally have ethyl acetate (solvent-like aroma) and ethyl hexanoate (apple-like aroma) as additional flavouring compounds with levels above the threshold (Meilgaard 1975b; Alvarez et al. 1994). However, for the vast majority of beers, other compounds like diacetyl (a vicinal diketone) should be found below the threshold values as it contributes negatively with a buttery flavour to the beer. Table 1 shows threshold values of the main esters and higher alcohols present in lager beer. As a full review of diacetyl 
Table 1 Threshold values of most important esters and higher alcohols present in lager beer (Engan 1974; Meilgaard 1975b; Engan 1981)

\begin{tabular}{|c|c|c|c|}
\hline Compound & $\begin{array}{l}\text { Threshold } \\
\left(\mathrm{mg} \mathrm{L}^{-1}\right)\end{array}$ & $\begin{array}{l}\text { Concentration } \\
\text { range }\left(\mathrm{mg} \mathrm{L}^{-1}\right)\end{array}$ & $\begin{array}{l}\text { Aroma } \\
\text { impression }\end{array}$ \\
\hline \multicolumn{4}{|l|}{ Acetate esters } \\
\hline Ethyl acetate & $25-30$ & $8-32$ & Fruity, solvent \\
\hline Isoamyl acetate & $1.2-2$ & $0.3-3.8$ & Banana \\
\hline Phenylethyl acetate & $0.2-3.8$ & $0.1-0.73$ & Roses, honey \\
\hline \multicolumn{4}{|l|}{ MCFA ethyl esters } \\
\hline Ethyl hexanoate & $0.2-0.23$ & $0.05-0.21$ & Apple, fruity \\
\hline Ethyl octanoate & $0.9-1.0$ & $0.04-0.53$ & Apple, aniseed \\
\hline \multicolumn{4}{|l|}{ Higher alcohols } \\
\hline$n$-Propanol & 600 & $4-17$ & Alcohol, sweet \\
\hline Isobutanol & 100 & $4-57$ & Solvent \\
\hline Isoamyl alcohol & $50-65$ & $25-123$ & Alcoholic, banana \\
\hline Amyl alcohol & $50-70$ & $7-34$ & Alcoholic, solvent \\
\hline 2-Phenylethanol & 40 & $5-102$ & Roses \\
\hline
\end{tabular}

formation was recently published (Krogerus and Gibson 2013), this paper will limit the discussion on the desirable odourants produced by the brewing yeast in the course of fermentation - higher alcohols and esters.

\section{Higher alcohols}

Also known as fusel alcohols, higher alcohols are the most abundant organoleptic compounds present in beer. The brewing yeast absorbs amino acids present in wort from which they take the amino group so it can be incorporated in its own structures. What is left from the amino acid ( $\alpha$-keto acid) enters in an irreversible chain reaction that will ultimately form a by-product - higher alcohols. This pathway was suggested long ago by Ehrlich (1907), who was intrigued with the structural molecular similarities between the active amyl alcohol with isoleucine and isoamyl alcohol with leucine. This observation has led Ehrlich to investigate whether these amino acids were involved in higher alcohol synthesis or not. When supplementing the fermenting medium with those amino acids, he evidenced an increased production of fusel alcohols. This observation led him to state that amino acids were enzymatically hydrolyzed to form the corresponding fusel alcohols, along with ammonia and carbon dioxide. As ammonia was not detected in the medium, it was assumed to be incorporated into yeast proteins. Few years later, Neubauer and Fromherz (1911) proposed a few intermediate steps to the Ehrlich pathway, completing the metabolic scheme as it is known until today. However, a detailed enzymatic chain reaction was only demonstrated several decades later (Sentheshanmuganathan and Elsden 1958; Sentheshanuganathan 1960), establishing the elementary enzymatic sequence for the Ehrlich pathway: transaminase, decarboxylase and alcohol dehydrogenase (Fig. 1). Although this pathway is the most studied and discussed, higher alcohols are also formed during upstream (anabolic pathway) biosynthesis of amino acids (Chen 1978; Dickinson and Norte 1993; Oshita et al. 1995). The most important is the de novo synthesis of branched-chain amino acids (BCAAs) through the isoleucine-leucine-valine (ILV) pathway (Dickinson and Norte 1993).

\section{Biosynthesis of higher alcohols}

\section{Transamination}

The first step in the Ehrlich pathway involves four enzymes encoded by the genes Bat1 (Twt1 or Eca39), Bat2 (Twt2 or Eca40), Aro8 and Aro9. These enzymes are transaminases that catalyse the transfer of amines between amino acids and their respective $\alpha$-keto acid, using glutamate $/ \alpha$-ketoglutarate as a donor/acceptor. While Bat1- and Bat2-encrypted enzymes are involved in the BCAA transamination (Eden et al. 1996; Kispal et al. 1996), Aro8p and Aro9p were first described as being aromatic amino acid aminotransferases I and II,

Fig. 1 The Ehrlich pathway and the main genes involved in the synthesis of enzymes catalyzing each reaction. The reversible transamination reaction uses different BAT-encrypted enzymes - while BAT2 catalyses the transfer of the amino group from the amino acid to $\alpha$ ketoglutarate (AKG), BAT1 is usually required on the reverse transamination for amino acid biosynthesis

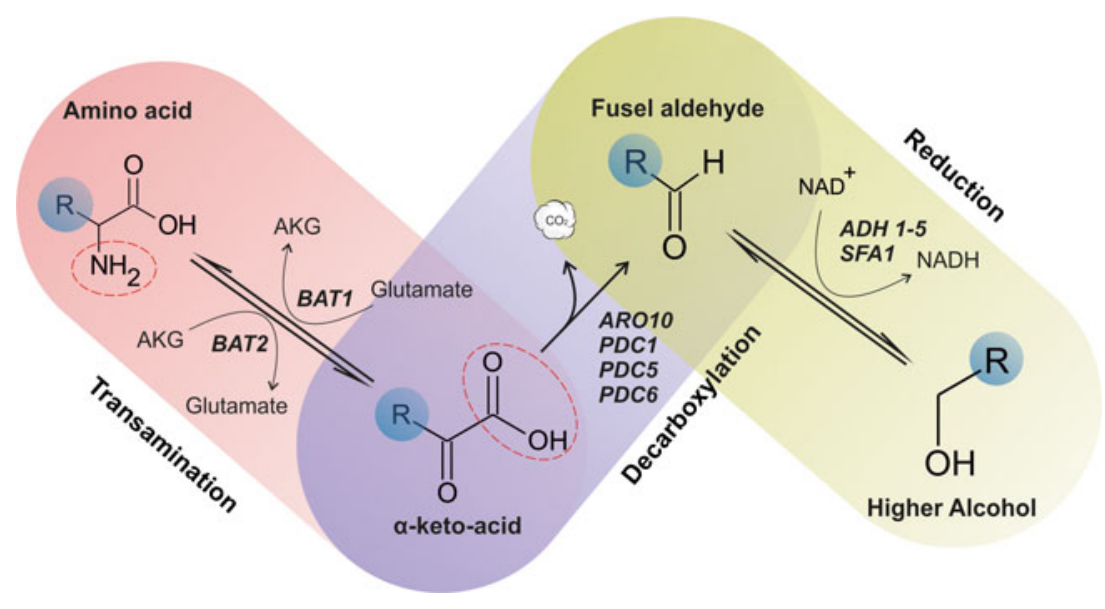


respectively (Iraqui et al. 1999). Further studies carried out by Urrestarazu et al. (1998) demonstrated that Aro8 and Aro9 encoded enzymes had broader substrate specificity than just for aromatic amino acids. This was confirmed in the work performed by Boer et al. (2007), who cultivated Saccharomyces cerevisiae using six independent nitrogen sources followed by transcriptome analysis. All phenylalanine, methionine and leucine activated the transcription of Aro9 and Bat2 genes.

A recent study mapped almost entirely (97\%) the proteome of S. cerevisiae (Picotti et al. 2013). The authors organized the proteome into a network of functionally related proteins, which they called as "modules". Within these modules, they highlighted one comprising of Bat1, Bat2, Rpn11, Hsp60 and Ilv2, which they termed B1B2 module. The core of this module is composed by Bat $1 \mathrm{p}$ and Bat $2 \mathrm{p}$ - two paralogous enzymes involved in the metabolism of the BCAAs. While Batlp is mainly involved in the anabolism of BCAAs (amination of $\alpha$-keto acids), Bat2p is almost exclusively involved in the catabolism of BCAAs (deamination of BCAAs). Thus, Bat1- and Bat2-encoded proteins catalyse the same metabolic reaction in opposite directions. Strictly related to these two proteins is the Ilv2-encrypted enzyme, which catalyses an early step in the synthesis of BCAAs from pyruvate (Picotti et al. 2013).

The subcellular location of enzymes catalyzing the synthesis of fusel alcohols has been studied in the past (Kispal et al. 1996; Schoondermark-Stolk et al. 2005) and recently emphasized (Avalos et al. 2013). Isobutanol is produced by yeast originally in the cytoplasm via the Ehrlich pathway or by anabolic synthesis inside the mitochondria (Kohlhaw 2003). Avalos et al. (2013) redirected the entire enzymatic biosynthetic pathway of that fusel alcohol to the mitochondrial matrix. Compartmentalization of the Ehrlich pathway within the mitochondria increased isobutanol production by $260 \%$, whereas overexpression of the same pathway in the cytoplasm only improved yields by $10 \%$. These results are justified by the more favorable environmental conditions found in the mitochondria matrix, which enhanced enzymatic activity.

\section{Decarboxylation}

After transamination, the remaining $\alpha$-keto acids can be decarboxylated to form the respective aldehyde and this is a point of no return in the Ehrlich pathway (Dickinson et al. 1997). There are five genes encoding decarboxylases in $S$. cerevisiae: three encoding pyruvate decarboxylases (PDC1, PDC5 and PDC6), ARO10 and THI3 (Dickinson et al. 1997; Romagnoli et al. 2012; Bolat et al. 2013), with all enzymes encrypted depending on the cofactor thiamine diphosphate (TPP). From within these genes, only PDC5 and ARO10 were described to encode decarboxylases with a broad substrate specificity (Vuralhan et al. 2003; Vuralhan et al. 2005; Romagnoli et al. 2012). Dickinson et al. (1998) have shown that valine is decarboxylated by any of the enzymes encrypted by PDC1, PDC5 or PDC6. In the case of isoleucine, all five decarboxylases of the family are able to produce active amyl alcohol (Dickinson et al. 2000). THI3encoded enzyme cannot catalyse the decarboxylation of the aromatic amino acids phenylalanine and tyrosine, while all other four can (Dickinson et al. 2003). The single expression of THI3 in a quadruple deleted ( $p d c 1 \Delta p d c 5 \Delta p d c 6 \Delta$ aro 10 $\Delta$ ) gene $S$. cerevisiae strain had no $\alpha$-keto acid decarboxylase activity (Vuralhan et al. 2003, 2005). Further studies involving THI3 suggest that its role in the Ehrlich pathway is rather regulatory than catalytic (Mojzita and Hohmann 2006).

Although the lager-brewing yeast Saccharomyces pastorianus is long known to be a natural aneuploid hybrid of S. cerevisiae with another Saccharomyces sp. (Vaughan and Kurtzman 1985), only recently the missing link was proven to be Saccharomyces eubayanus (Libkind et al. 2011). This fact has called the attention of Bolat et al. (2013) upon the contribution of ARO10 gene expression from each of the subgenomes on the production of higher alcohols. The authors amplified by PCR both $S$. eubayanus-like and $S$. cerevisiaelike alleles of ARO10 ( $L g S e u b A R O 10$ and $L g S c A R O 10$, respectively) from the genomic DNA of $S$. pastorianus. The alleles showed a sequence identity of $80 \%$ at the DNA level and $84 \%$ at the protein level. The results have also shown that S. cerevisiae alleles of ARO10 are present in a ratio of 3:1 from those present in S. eubayanus subgenome. These authors have equally demonstrated that both $S$. eubayanus-like and S. cerevisiae-like ARO10-encoded isoenzymes had similar activity for most of the substrates tested with preferred decarboxylation action against phenylpyruvate. However, the ac-

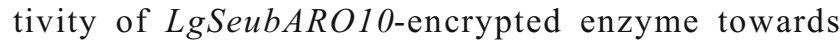
ketoisovalerate (precursor of isobutanol) was twofold higher than that encoded by LgScARO10. Moreover, those authors also suggest that $S$. eubayanus-like and $S$. cerevisiae-like ARO10-derived $\alpha$-oxo acid decarboxylases exert different roles during beer fermentation by S. pastorianus. Fusel alcohols produced by the Ehrlich pathway would involve preferentially the $S$. cerevisiae-ARO10 decarboxylase. Conversely, higher alcohols formed by de novo synthesis would rely almost exclusively on the LgSeubARO10-encrypted isoenzyme.

\section{Reduction to higher alcohols}

After decarboxylation, the fusel aldehydes enter in the last step of the Ehrlich pathway, where they are converted into their respective alcohols by action of alcohol dehydrogenases. Any one of the $S$. cerevisiae alcohol dehydrogenases encoded by Adh1, Adh2, Adh3, Adh4 and Adh5 or the formaldehyde dehydrogenase encrypted by Sfa1 is able to catalyse the conversion of fusel aldehydes into higher alcohols 
(Dickinson et al. 2003). Thus, studies related to these genes often discuss ethanol production rather than fusel alcohols. Adh1-encoded enzyme is the constitutive, cytoplasmic form that reduces acetaldehyde into ethanol during fermentation (Bennetzen and Hall 1982). Adh2p is also a cytoplasmic enzyme, but it is directly repressed in the presence of glucose acting in the opposite direction of Adh $1 \mathrm{p}$ by oxidizing ethanol (Russell et al. 1983; Picotti et al. 2013). Contrary to cytosolic counterparts, Adh $3 p$ is responsible for the reduction of acetaldehyde inside the mitochondria in order to keep the redox balance during anaerobic growth (Bakker et al. 2000).

\section{Regulation of higher alcohols}

Iraqui et al. (1999) were the first to identify the Aro 80 gene as a pathway-specific regulator of the Aro9 transaminase and Aro10 decarboxylase in the presence of the aromatic amino acids tryptophan, phenylalanine and tyrosine. The nitrogen catabolite repression (NCR) on S. cerevisiae is mediated by GATA transcription factors consisting of activators (Gat1 and Gln3) and repressors (Gzf3 and Dal80) (Hofman-Bang 1999). The NCR works as a global nitrogen quality control system, activating GATA genes in the presence of poor nitrogen sources and repressing them when nitrogen-rich materials are available (Cooper 2002). Recent findings have shown that Aro9 and Aro10 transcription also requires GATA activators (Lee and Hahn 2013). In other words, Aro80 not only induces the transcription of Aro9 and Aro10 by directly binding to their promoters in the presence of aromatic amino acids but also is required for the recruitment of Gat1 and Gln3 activators. Lee et al. (2013) assessed whether environmental conditions would also affect Aro9 and Aro10 expression. Among the conditions tested, only heat shock stress was able to activate Aro9 and Aro10 transcription. Furthermore, the authors tested a knockdown aro $80 \Delta$ strain upon the same stress conditions and no Aro9 or Aro10 expression was observed in heat shock growth. These data strongly suggest that the transcription of Aro9 and Aro 10 is activated by Aro 80 under heat shock stress in S. cerevisiae. Back in the study of Bolat et al. (2013) with S. pastorianus, a deletion of Aro80 from S. eubayanus-like allele did not eliminate phenylalanine induction of LgSeubARO10. This finding suggests that LgScAro80 can also cross-activate LgSeubARO10 compensating the loss of an S. cerevisiae-type activator.

\section{Anabolic pathway}

The brewing wort normally has all proteinogenic amino acids required by the fermenting yeast to grow. However, $\alpha$-keto acids (intermediates in the Ehrlich pathway) are also formed via the de novo biosynthesis of amino acids through carbohydrate metabolism (Fig. 2) (Chen 1978). Thus, in order to evaluate the contribution of anabolic pathway in the synthesis of higher alcohols, Eden et al. (2001) have blocked the

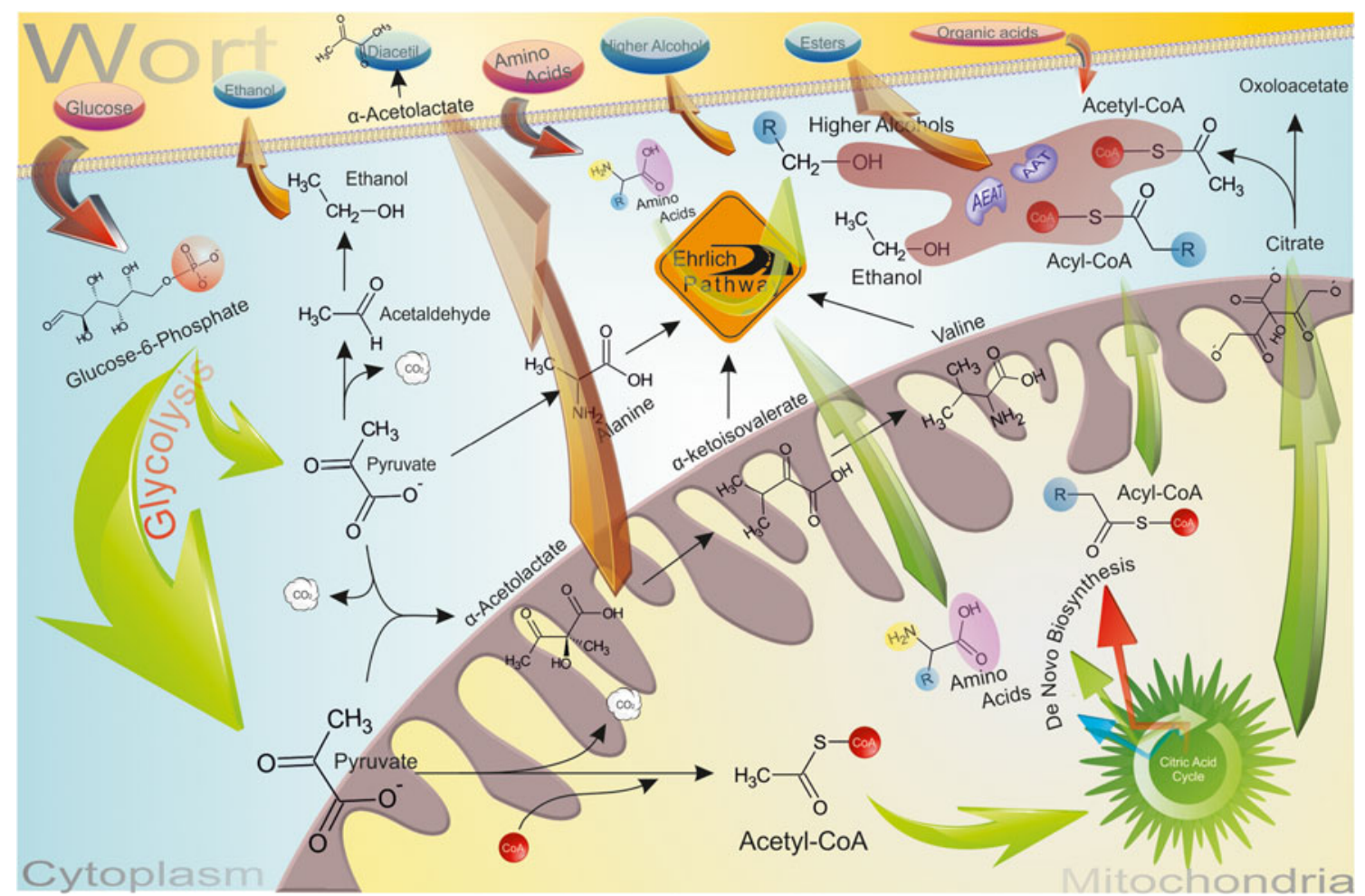

Fig. 2 A schematic overview of the main metabolic routes inside brewing yeast cell contributing to the synthesis of higher alcohols and esters when inserted in the fermenting wort 
transamination of amino acids from the growth medium by using a knockout strain (eca39 $\Delta$ and eca $40 \Delta$ ). In addition to these deletions, $i l v 2 \Delta$ was also investigated, and thus, the activity of acetolactate synthase (ILV2) could be assessed. Without ILV2, the synthesis of isoleucine is hindered, causing an increase of the main precursor (after pyruvate) $-\alpha$ ketobutyrate. As this $\alpha$-keto acid is the precursor of propanol, the authors evidenced a significant increase in this fusel alcohol produced by eca39 $\Delta$ eca $40 \Delta$ ilv $2 \Delta$ strain (Eden et al. 2001). This strain was also unable to produce isobutanol as $\alpha$ acetolactate could not be synthetized from pyruvate due to lack of ILV2. Thus, as no external amino acid could be used in the Ehrlich pathway due to eca39 $\Delta$ eca $40 \Delta$, the role of ILV2 gene was confirmed in the anabolic pathway of isobutanol. On the other hand, the synthesis of active amyl alcohol and isoamyl alcohol was reduced, but still unexpectedly present (Eden et al. 2001). ILV2 was recently addressed to be integrated to a protein network module of functional similar proteins involved in BCAAs and physically connected to the mitochondria (Picotti et al. 2013).

\section{Esters}

Compared to other yeast metabolites, esters are only trace elements. Nevertheless, despite being "a drop in the ocean" of beer's constituents, esters are the most important aroma elements produced by yeast. That is because esters have a very low odour threshold in beer (Meilgaard 1975b; Saison et al. 2009) and, yet to a large extent, may define its final aroma (Engan 1974; Suomalainen 1981; Nykanen and Suomalainen 1983; Peddie 1990; Meilgaard 1991; Saerens et al. 2008a; Saison et al. 2009; Verbelen et al. 2009; Hiralal et al. 2013). However, if overproduced, they can negatively affect the beer with a bitter, over fruity taste. Thus, it is crucial for the brewer to keep the optimum conditions to obtain a balanced beer in terms of its ester profile.

Esters are mainly formed during the vigorous phase of primary fermentation by enzymatic chemical condensation of organic acids and alcohols. Volatile esters in beer can be divided in two major groups: the acetate esters and the medium-chain fatty acid (MCFA) ethyl esters. The former group comprises esters synthetized from acetic acid (acetate) with ethanol or a higher alcohol. In the ethyl esters' family, ethanol will form the alcohol radical and the acid side is a MCFA. Although dozens of different esters can be found in any beer (Engan 1974; Meilgaard 1975b), six of them are of major importance as aromatic constituents: ethyl acetate (solvent-like aroma), isoamyl acetate (banana aroma), isobutyl acetate (fruity aroma), phenyl ethyl acetate (roses and honey aroma), ethyl hexanoate (sweet apple aroma) and ethyl octanoate (sour apple aroma).
Esters are synthetized in the cytoplasm of the brewing yeast, but readily leave the cell as they are lipophilic. However, while small-chain acetate esters easily diffuse through the plasmatic membrane, MCFA ethyl esters may have their passage hindered (Nykanen and Nykanen 1977; Nykiinen et al. 1977; Dufour 1994).

To be synthetized into esters, organic acids must be linked to a coenzyme A to form an acyl-CoA molecule. Acyl-CoAs are highly energetic entities, which in the presence of oxygen can be $\beta$-oxidized ("cut") into smaller units (acetyl-CoA) in the mitochondria. This will happen unless the organic acid involved is the acetic acid itself, which in this case will be turned into acetyl-CoA. However, the great majority of acetyl-CoA produced by the yeast cells comes from the oxidative decarboxylation of pyruvate. Aerobic conditions inside the mitochondria make acetyl-CoA to enter in the Krebs cycle to form ATP (respiration). In the absence of oxygen, acetyl-CoA will be enzymatically esterified with an alcohol to form the acetate esters. Moreover, MCFA ethyl esters are formed from longer chains of acyl-CoA with ethanol. Figure 2 drafts the main metabolic routes of the brewing yeast contributing to higher alcohols and ester synthesis.

\section{Biosynthesis of acetate esters}

Acetate esters are the major flavour components of beer as they are present in much higher concentrations than other volatile esters. The enzymatic involvement of synthases on ester production dates from the 1960s (Nordström 1962), but the enzyme was only purified and named as alcohol acetyltransferase (AATases) back in 1981 by Yoshioka and Hashimoto (1981). The most studied and best characterized enzymes responsible for ester synthesis are AATases I and II (EC 2.3.1.84), encoded by the genes ATF1 and ATF2 (Yoshioka and Hashimoto 1981; Malcorps and Dufour 1992; Fujii et al. 1994; Nagasawa et al. 1998; Yoshimoto et al. 1998; Verstrepen et al. 2003b; Molina et al. 2007; Dekoninck et al. 2012; Zhang et al. 2013). It was also found that bottomfermenting lager yeasts have an extra ATF1 homologous gene (Lg-ATF1) (Fujii et al. 1994), which encodes an AATase very similar to that encoded from the original ATF1 gene (Fujii et al. 1996). This additional gene expression on lager yeast enhances acetate ester production and ultimately beer's aroma profile.

The best way to understand the role of a gene's expression is by either overexpressing or deleting it. A heavy body of literature focus on these genetic modifications to better understand the role of ATF1, ATF2 and Lg-ATF1 gene expression on the total acetate ester production (Fujii et al. 1994, 1996; Nagasawa et al. 1998; Yoshimoto et al. 1998; Verstrepen et al. 2003b; Zhang et al. 2013). Very recently, a brewer's yeast 
strain was designed to increase ester/higher alcohol ratio by overexpressing ATF1 and knocking down a gene related to higher alcohol synthesis (Zhang et al. 2013). Ester production by the genetically modified strains was considerably higher than that of parental cells. Verstrepen et al. (2003b) have earlier carried out a more detailed work concerning deletion and overexpression not only of the AFT1 but also of its homologous Lg-ATF1 as well as ATF2. As others in the past (Fujii et al. 1994, 1996; Nagasawa et al. 1998), those authors clearly demonstrated the strong impact exerted by the expression levels of ATF genes on acetate ester production. For example, they have shown that overexpressing ATF1 strains may have up to 180 -fold increased isoamyl acetate production and a 30-fold increased ethyl acetate production when compared to wild-type cells. In fact, their analysis also revealed that ATF1-encrypted ATTases seem to be responsible for the great majority of acetate ester production. Through specific deletion of ATF1 and ATF2, no acetate esters originated from alcohols with more than five carbon atoms, like isoamyl acetate and phenyl ethyl acetate, were formed. This means that the most desirable banana aroma (isoamyl acetate) in beer depends exclusively on ATF1- and ATF2-encoded enzymes. Later, Saerens et al. (2008b) confirmed that the maximum expression levels of ATF1 and ATF2 are directly correlated to the final concentration of acetate esters. However, the knockdown (atfl $\Delta$ at $2 \Delta)$ executed by Verstrepen et al. (2003b) could only reduce the production of smaller esters such as ethyl acetate by $50 \%$. Together with other pieces of evidence (Malcorps et al. 1991; Malcorps and Dufour 1992), this result makes clear that there might be more ATTases involved on acetate ester production, but this goes beyond the knowledge present in published data. Figure 3a schematizes the chemical reaction for the production of the main acetate esters and genes involved in these reactions.

The presence of acetate esters on alcohol-free beers (AFBs) is imperative. AFBs can be produced either from physical removal of ethanol from the finished beer or by controlling the biological process involved in beer fermentation (Branyik et al. 2012). AFBs produced by membrane processes have usually less body and a low aromatic profile, thermally dealcoholized AFBs may suffer heat damages, while beers obtained by biological methods have often a sweet and worty off-flavour (Montanari et al. 2009). The lack of ethanol itself greatly affects the retention of volatile aroma-active compounds (Perpete and Collin 2000). Very recently, Strejc et al. (2013) isolated a brewing yeast mutant capable of overproducing isoamyl acetate and isoamyl alcohol. The sweet banana odour from isoamyl acetate could then be a solution to overcome the undesirable worty off-flavour of AFB. Sensory analyses showed that the increased level of isoamyl acetate ester had a positive effect on the fruity (banana) palate fullness and aroma intensity of the AFB produced.

\section{Biosynthesis of ethyl esters}

When inserted in all history of volatile ester research, MCFA ethyl esters received less attention from the literature in the past. This happened because they are much less present in beer compared to their acetate counterparts. Nonetheless, works focused on ethyl esters in brewing fermentations have become much more common in the past decade, most of them were carried out by Saerens et al. (2006, 2008a). Before them, with evidence published long ago (Malcorps and Dufour 1992), Mason and Dufour (2000) suggested that apart from ATF1- and ATF2-encoded enzymes, there should be a different enzyme involved on ethyl ester synthesis. This estersynthesizing enzyme, called ethanol hexanoyl transferase, is responsible for generating ethyl hexanoate from ethanol and hexanoyl-CoA (Mason and Dufour 2000). Later in 2006, Saerens and coworkers proved that MCFA ethyl esters are produced by the brewing yeast through a condensation reaction between an acyl-CoA unity and ethanol (Fig. 3b), catalysed by two acyl-CoA/ethanol $O$-acyltransferases (AEATases) encoded by Eeb1 and Eht1 genes (Saerens et al. 2006). Moreover, these authors were highly convinced of the role of each of these genes on the final MCFA ethyl ester content. A single deletion on EeB1 reduced the formation of ethyl butanoate, ethyl hexanoate, ethyl octanoate and ethyl decanoate in 36, 88, 45 and $40 \%$, respectively. Eht1 knockout strain on the other hand only had ethyl hexanoate and ethyl octanoate production affected. Additionally, a double-deletion (eeb1 $\Delta$ and eht $1 \Delta$ ) strain produced a similar ethyl ester profile to the eeb1 $\Delta$ single-deletion strain. This means that EeB1 is the most relevant gene on MCFA ethyl ester synthesis (Saerens et al. 2006). However, even though double deletion caused a pronounced drop in ethyl esters measured, only ethyl hexanoate production was virtually extinguished. Thus, there must be other, yet unknown, AEATases involved on the MCFA ethyl ester synthesis. Also, overexpression of those genes did not increase MCFA ethyl ester production even when more precursors of these esters were added to the fermenting medium. This fact was explained as a consequence of extra esterase (breakdown) activity exerted by Eeb1- and Eht1-encoded proteins, which was also demonstrated in vitro by the same authors (Saerens et al. 2006).

\section{Ester regulation}

The net rate of ester production depends not only on the availability of the precursor's substrates (Saerens et al. 2006; Hiralal et al. 2013) but also, to a significant extent, on the enzymatic balance of synthesis (by AATases) (Yoshimoto et al. 1998; Mason and Dufour 2000; Verstrepen et al. 2003b; Saerens et al. 2006; Zhang et al. 2013) and breakdown (by esterases) of esters (Fukuda et al. 1996; Fukuda et al. 
Fig. 3 A scheme of the chemical reactions involving the biosynthesis of acetate esters (a) and medium-chain fatty acid ethyl esters (b). The main genes involved in each reaction are presented above the reaction arrows

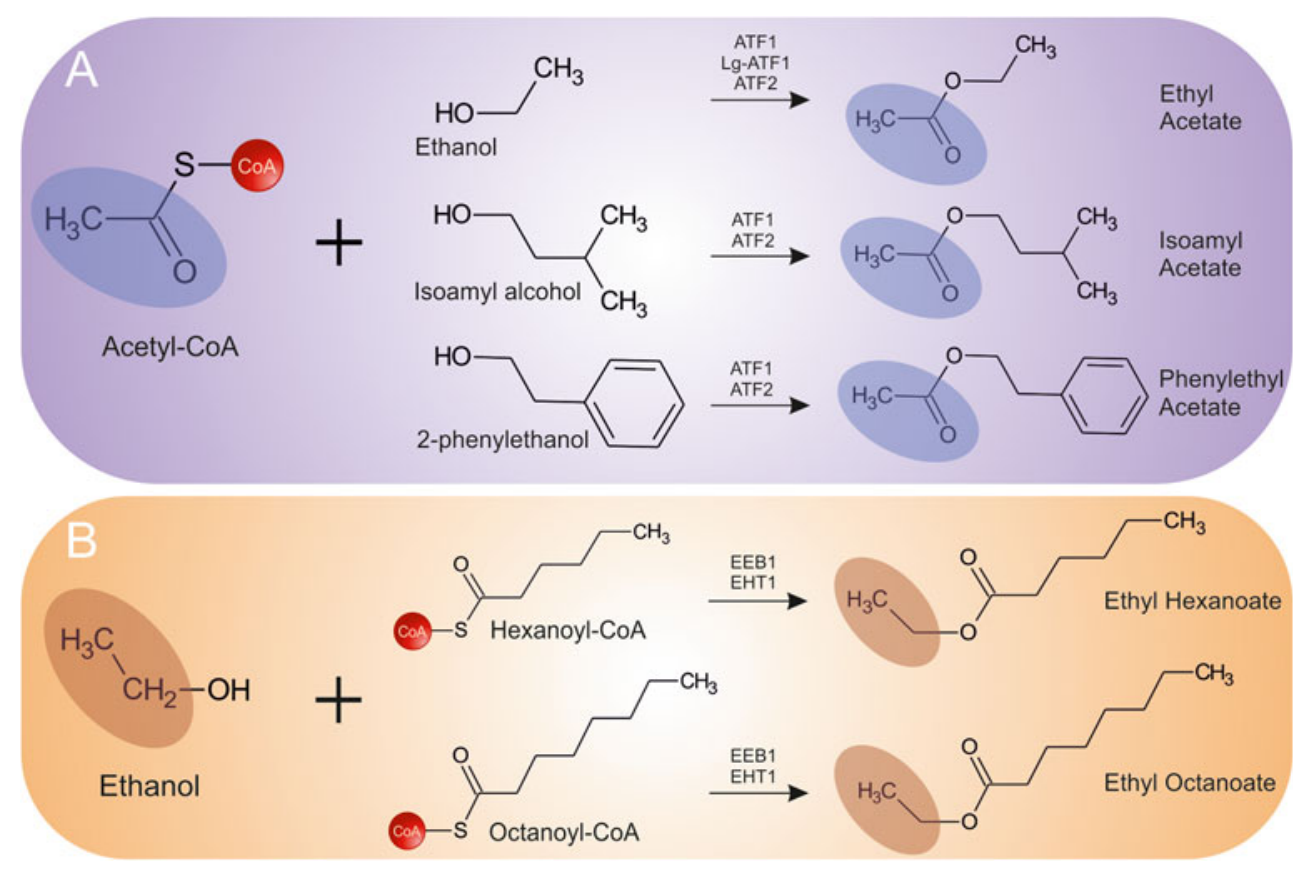

1998a; Lilly et al. 2006). Esterases are a group of hydrolyzing enzymes that catalyse the cleavage and/or avoid the formation of ester bonds. Fukuda et al. (1998b) have chosen another strategy to raise the end net of isoamyl acetate production by a sake strain of $S$. cerevisiae. Instead of enhancing AATases' activity, they avoided isoamyl acetate cleavage by deleting the acetate-hydrolyzing esterase gene (IAH1, previously known as EST2) responsible for encoding the carboxylesterase that hydrolyzes that ester (Fukuda et al. 1996). The mutantdeficient strain produced approximately 19 times higher amounts of isoamyl acetate when compared with the parent strain. Fukuda et al. (1998a) have further proven the important balance activity between AATases and esterases for the net rate of ester accumulation by S. cerevisiae. More evidence of the IAH1-encoded esterase on the breakdown of esters was built up recently by Lilly et al. (2006). In addition to isoamyl acetate, the authors also reported decreased production of ethyl acetate, phenyl ethyl acetate and hexyl acetate by the overexpressing IAH1 mutant strain. These findings are in agreement with the recent published data by Ma et al. (2011) whose work determined the crystalline structure of the enzyme encrypted by IAH1 gene. They have shown that an additional C-terminus was involved on the substrate-binding region. Furthermore, it was also demonstrated that this Cterminus restricts access to the active site of the enzyme, playing a vital role in determining substrate specificity. Nonmodified IAH1-encoded esterase had the highest hydrolytic activity against shorter acetate esters. Moreover, this activity was greatly reduced against ethyl hexanoate and almost null for ethyl decanoate, which suggests that IAH1-encrypted enzyme is more specific for shorter-chain esters. This was confirmed by truncating the additional C-terminus present in the enzyme. This modified variant was now able to hydrolyze longer ethyl ester chains such as decanoate. Those authors concluded that deletion of the C-terminus provides better access to the active site of the enzyme, which allows it to accommodate longer acyl chains (Ma et al. 2011).

\section{Esters on aging beer}

The ester profile of a given beer may change drastically during storage either by action of yeast (bottle refermentation) (Vanderhaegen et al. 2003) or by spontaneous chemical condensation of organic acids with ethanol (Vanderhaegen et al. 2006; Saison et al. 2009; Rodrigues et al. 2011). With time, hop-derived components are oxidized to form 3methylbutyric and 2-methylbutyric acids, which are spontaneously esterified to their respective ethyl esters (3methylbutyrate and 2-methylbutyrate) (Williams and Wagner 1979) that impart the aged beer a winy aroma (Williams and Wagner 1978). On the other hand, some esters as isoamyl acetate are known to be hydrolyzed during beer storage (Neven et al. 1997). Chemical hydrolysis and esterification are acid-catalysed (Vanderhaegen et al. 2006), but the remaining esterases from yeast autolysis can also play their role in unpasteurized beers (Neven et al. 1997). Other ethyl esters as ethyl nicotinate (medicinal, solvent, anis-like aromas), ethyl pyruvate (peas, freshly cut grass) and ethyl lactate (fruity, buttery) are also formed in aging beers (Saison et al. 2009). For all reasons mentioned in these lines, aging beers tend to lose fresh fruity aromas, giving place to sweeter odours. 


\section{Yeast response to fermentation parameters}

Yeast strain

As regards the lines written above, it is easy to conclude that the production of most aroma-active compounds is strictly dependent on the yeast strain chosen for the fermentation. The genome associated to each strain is unique and will ultimately define the final aroma profile of the product (Ramos-Jeunehomme et al. 1991; Rossouw et al. 2008). This makes the selection of the right strain the most important task to make good beer. Yet, it is crucial that the brewer keeps his strain safe not only from "wild" yeast contaminations but also from genetic drifts that may occur in the course of serial repitching (Sato et al. 1994; Jenkins et al. 2003; Powell and Diacetis 2007). While the repeated repitching processes will not cause prominent loss of physiological characteristics of the brewing yeast (Powell and Diacetis 2007; Buhligen et al. 2013; Vieira et al. 2013), the accumulation of variants may eventually cause certain characteristics to linger on subsequent generations. That is why brewers must keep frozen stocks of their yeast strains for periodical restart of fresh pitching cultures.

\section{Temperature}

It has been reported that rising fermentation temperatures increase BAP2 expression in the brewing yeast $S$. cerevisiae (Yukiko et al. 2001). This gene is responsible for encoding a broad-substrate specificity permease that promotes the transport of the BCAAs valine, leucine and isoleucine into the yeast cell (Didion et al. 1996). The higher availability of amino acids within the cell favor the catalytic Ehrlich pathway, increasing higher alcohol production (Yukiko et al. 2001). Saerens et al. (2008b) obtained increasing levels of propanol, isobutanol, isoamyl alcohol and phenyl ethanol by rising the fermentation temperature using two different brewing yeast strains. Conversely, those authors have shown that although increasing temperatures promote the expression of all BAT1, BAT2 and BAP2, only BAT1 could be strongly correlated with the final concentration of higher alcohols, in particular of propanol (Saerens et al. 2008b).

As higher alcohol formation is temperature-dependent (Landaud et al. 2001), changes in temperature may cause changes in the availability of fusel alcohols, which are necessary for ester formation (Calderbank and Hammond 1994). Indeed, a slight change in temperature from 10 to $12{ }^{\circ} \mathrm{C}$ can increase ester production of up to $75 \%$ (Engan and Aubert 1977). Saerens et al. (2008b) have shown that the AATaseencrypting genes ATF1 and ATF2 are more expressed with increasing temperatures during beer fermentation. Furthermore, the maximum expression of these genes clearly correlated with the end concentration of ethyl acetate, isoamyl acetate and phenyl ethyl acetate.

Hydrostatic pressure

With increasing market demands, breweries are continuously increasing reactor sizes for beer production. The incredibly high fermenters naturally generate a huge hydrostatic pressure that generally increases the concentration of carbon dioxide dissolved in beer. The excess in dissolved $\mathrm{CO}_{2}$ inhibits yeast growth by unbalancing decarboxylation reactions (Rice et al. 1977; Knatchbull and Slaughter 1987; Renger et al. 1992; Shanta Kumara et al. 1995; Landaud et al. 2001). As said before, decarboxylation is a fundamental step in either higher alcohol or acetyl-CoA synthesis. As acetyl-CoA is the main precursor of acetate esters, hydrostatic pressure unbalances beer flavour most probably by limiting the substrate availability for ester formation (Landaud et al. 2001).

\section{Wort composition}

It is not hard to understand that wort's composition will greatly influence the final beer aroma. After all, fermenting wort is nothing more than a growth medium from which the brewing yeast absorbs nutrients for living and to where it lays its metabolic by-products. Thus, changes in the nutrient content will trigger different yeast responses.

\section{Sugars}

High-gravity brewing (HGB) or even very high-gravity (VHG) brewing became a common practice for commercial breweries as it can bring great economic benefits (Yu et al. 2012; Lei et al. 2013b). The use of HGB can not only increase the brewery capacity in up to $20-30 \%$ without any investment in equipment but also improve the haze and smoothness of the beer (Stewart 2007). However, HGB often brings an unbalanced flavour profile to the finished beer, being the most common perturbation the overproduction of acetate esters, impairing the beer with over-fruity and solvent-like aromas (Anderson and Kirsop 1974; Peddie 1990; Saerens et al. 2008b). Anderson and Kirsop (1974) observed up to an eightfold increase in acetate ester production when the specific gravity of wort was doubled. Saerens et al. (2008b) have tested ale and lager strains upon increasing specific wort gravity. Although all higher alcohols measured showed an increased accumulation, after dilution to reach the normal ethanol content $(5.1 \%, v / v)$, only the fermentations performed by the ale strain remained with unbalanced high levels of fusel alcohols. Additionally, all acetate esters were overproduced by both lager and ale strains when increasing the initial specific gravity of the fermenting wort. Yet, not only the amount but also the type of sugars may influence the changes in the 
aromatic profile of the final beer. Easily assimilable glucoseand fructose-rich worts normally generate beers with higher contents of esters than those rich in maltose (Younis and Stewart 1998, 1999, 2000; Piddocke et al. 2009). Both 21 and $24{ }^{\circ} \mathrm{P}$ worts enriched with maltose syrup fermentations performed by Piddocke et al. (2009) produced less acetate esters compared to fermentations carried out with glucose syrup-enriched worts. The reason why an individual assimilable sugar has a different impact on ester production is still unknown. Younis and Stewart (1998) suggested that higher levels of glucose increase acetyl-CoA, which is the main substrate for acetate ester synthesis. In the same way, maltose-rich worts may weakly induce acetyl-CoA formation for acetate ester production (Shindo et al. 1992). Moreover, while glucose rapidly enhances ester synthase activity in carbon-starved cells by directly inducing ATF1 transcription through Ras/cAMP/PKA nutrient pathway, maltose relies on the slow "fermentable growth medium-induced" (FGM) pathway to do so (Verstrepen et al. 2003a). Furthermore, a nitrogen source is needed to maintain the transcription of ATF1 and LgATF1 in the course of the fermentation (Verstrepen et al. 2003a). Increasing levels of maltose as a sole carbon source in a synthetic medium showed an increasing tendency to accumulate acetate esters (Saerens et al. 2008a). Conversely, Dekoninck et al. (2012) have shown that although sucrose had a higher impact on ATF1 expression when compared to maltose, a remarkable decrease in acetate esters was observed during HGB. The high amount of sucrose stimulated yeast's metabolism and growth which ultimately increased the uptake of amino acids. This discussion leads to another important factor on HGB altering aroma profile of the beer - the carbonto-nitrogen $(\mathrm{C} / \mathrm{N})$ ratio. The addition of sugary syrups is a common practice to increase the specific gravity of the wort in HGB. However, these syrups generally lack nitrogen, which normally reduces the total free amino nitrogen (FAN) content of the wort. Therefore, adjuncts usually increase the $\mathrm{C} / \mathrm{N}$ ratio, which in turn may lead nitrogen to be a growth-limiting factor (Verstrepen et al. 2003a; Saerens et al. 2008a; Lei et al. 2012, 2013a). Any alteration in sugar or FAN levels affects acetate ester accumulation, but not ethyl esters (Saerens et al. 2008a). Additionally, diluted FAN content observed in HGB leads to abnormal yeast physiology and unbalanced beer flavour (Lei et al. 2012).

\section{FANs}

Although a wide range of nitrogen-containing compounds are dissolved in the wort, the brewing yeast can only assimilate the smaller molecules, generally called FANs. The discussion of FANs interfering with beer aroma will inevitably lead to the absorption of amino acids to form higher alcohols through the Ehrlich pathway. The type and amount of amino acids will also lead the yeast to different responses and ultimately to final beer aromatic profile (Äyräptää 1971; Lei et al. 2013a). In fact, treating the wort with proteases increases the final FAN and ultimately increases the higher alcohols and esters by the brewing yeast in either HGB or normal gravity brewing (Lei et al. 2013c). The addition of BCAAs like valine, leucine and isoleucine to the fermenting wort increases the formation of their respective fusel alcohols - isobutanol, isoamyl alcohol and amyl alcohol (Engan 1970; Äyräptää 1971; Procopio et al. 2013). Recently, Procopio et al. (2013) have shown that not only the addition of valine, leucine and isoleucine increased the formation of fusel alcohols but intriguingly also did proline. Since proline cannot be converted into a higher alcohol via the Ehrlich pathway, its role on fusel alcohol formation induction was attributed to the synthesis of glutamate from this amino acid. A recent study showed that the supplementation of wort with lysine and histidine improved the performance of a lager brewing yeast in HGB (Lei et al. 2013a). Compared to lysine, histidine greatly affected the aromatic profile by increasing the formation of higher alcohols and ester. Moreover, recent reports confirmed that FAN content of wort can affect the transcription of both ATF1 and BAT1 genes (Saerens et al. 2008b; Lei et al. 2012).

\section{Oxygen and unsaturated fatty acids}

Dissolved oxygen and unsaturated fatty acids (UFAs) in wort are remarkably known as negative regulators of ester synthesis by brewing yeast (Anderson and Kirsop 1974; Anderson and Kirsop 1975a, b; Taylor et al. 1979; Thurston et al. 1982; Malcorps et al. 1991; Fujii et al. 1997, Fujiwara et al. 1998). Oxygen was once thought to indirectly reduce ester formation by decreasing acetyl-CoA availability (Anderson and Kirsop 1974). However, when genetic studies came into fashion, oxygen and UFAs were proven to directly inhibit the expression of ATF1 and ATF2 (Fujii et al. 1997). Fujiwara et al. (1998) have further complemented that oxygen and UFAs repress the expression of ATF1 by different regulatory pathways. While the repression of ATF1 by oxygen is mediated by the Rox1-Tup1-Ssn6 hypoxic repressor complex (Fujiwara et al. 1999), UFAs intermediate through the low-oxygen response element (Vasconcelles et al. 2001). In addition to acetate esters, it has been also shown that increasing levels of UFAs in the fermenting medium reduce the production of ethyl esters by the brewing yeast (Saerens et al. 2008a).

Considering what is written above, Moonjai et al. (2002) assessed the potential of rich UFA lipid supplements to decrease the need of wort aeration. The results have shown that the treated yeast with UFAs can be pitched into pooroxygenated worts without losing fermentation potency or organoleptic quality. A reduced amount of oxygen supplied to the wort may increase flavour stability of the final beer and will limit potential oxidative stress upon the brewing yeast (Gibson et al. 2008). Inspired by this potential, Hull (2008) 
assessed the replacement of wort oxygenation by treatment of the pitching yeast with olive oil rich in UFAs. The industrial-scale test succeeded without major effects on the acceptability of the beer produced. Therefore, UFA-treated yeast may be of particular help on HGB, once worts with specific high gravity have limited oxygen solubility (Baker and Morton 1977).

\section{Conclusions}

Formation of higher alcohols and esters by brewing yeast involves complex enzymatic and regulatory pathways. Nonetheless, much progress has been made in elucidating not only the genes involved in the transcription of key enzymes during the biosynthesis of these aroma-active substances but also on the importance of the subcellular location of these enzymes inside the yeast cell. Also, important steps have been taken towards substrate specificity as regards the analysis of the crystalline structure of IAH1-encoded esterase for small acetate esters.

Much progress has been also done in proteomics describing the B1B2 module of functionally related proteins. The core of this module is composed by Bat $1 \mathrm{p}$ and Bat $2 \mathrm{p}$ - two paralogous enzymes involved in the metabolism of the BCAAs catalyzing the same metabolic reaction in opposite directions. It was also interesting to know the contribution of the subgenomes of S. pastorianus to the final concentration of higher alcohols. Fusel alcohols originated from the catabolic pathway involve preferentially the S. cerevisiae-ARO10 decarboxylase. Conversely, higher alcohols formed by de novo synthesis rely almost exclusively on the LgSeubARO10encrypted isoenzyme.

While acetate ester production is largely dependent on ATF1- and ATF2-encoding enzymes, substrate concentration seems to be the major limiting factor for ethyl ester synthesis.

The bad aspects involving HGB affecting beer aroma are still a reality. However, each day, breweries and scientists head forward to overcome these problems. Not only genetically modified brewing yeasts are being developed but also interesting techniques like pretreatment of pitching yeast with oilrich UFAs to substitute wort oxygenation are being applied. In addition to those well-known BCAAs valine, leucine and isoleucine increasing the formation of their respective fusel alcohols (isobutanol, isoamyl alcohol and amyl alcohol), proline interestingly can also raise the end net of fusel alcohols through the formation of glutamate - a key compound in yeast metabolism that may be used as an amine donor in amino acid synthesis.

Despite the clear progress describing fusel alcohols and ester synthesis by brewing yeast, there is still much to be found in this field.
Acknowledgments Eduardo Pires gratefully acknowledges the Fundação para a Ciência e a Tecnologia (FCT, Portugal) for the $\mathrm{PhD}$ fellowship support (SFRH/BD/61777/2009). The financial contributions of the EU FP7 project Ecoefficient Biodegradable Composite Advanced Packaging (EcoBioCAP, grant agreement no. 265669) as well as of the Grant Agency of the Czech Republic (project GAČR P503/12/1424) are also gratefully acknowledged. The authors thank the Ministry of Education, Youth and Sports of the Czech Republic (MSM 6046137305) for their financial support.

\section{References}

Alvarez P, Malcorps P, Almeida AS, Ferreira A, Meyer AM, Dufour JP (1994) Analysis of free fatty-acids, fusel alcohols, and esters in beer - an alternative to Cs2 extraction. J Am Soc Brew Chem 52: $127-134$

Anderson RG, Kirsop BH (1974) The control of volatile ester synthesis during the fermentation of wort of high specific gravity. J Inst Brew 80:48-55

Anderson RG, Kirsop BH (1975a) Oxygen as a regulator of ester accumulation during the fermentation of worts of high specific gravity. $\mathrm{J}$ Inst Brew 81:111-115

Anderson RG, Kirsop BH (1975b) Quantitative aspects of the control by oxygenation of acetate ester formation of worts of high specific gravity. J Inst Brew 81:269-301

Avalos JL, Fink GR, Stephanopoulos G (2013) Compartmentalization of metabolic pathways in yeast mitochondria improves the production of branched-chain alcohols. Nat Biotechnol 31:335-341

Äyräptää T (1971) Biosynthetic formation of higher alcohols by yeast. Dependence on the nitrogen nutrient level of the medium. J Inst Brew 77:266-276

Baker CA, Morton S (1977) Oxygen levels in air-saturated worts. J Inst Brew 83:348-349

Bakker BM, Bro C, Kotter P, Luttik MA, van Dijken JP, Pronk JT (2000) The mitochondrial alcohol dehydrogenase Adh3p is involved in a redox shuttle in Saccharomyces cerevisiae. J Bacteriol 182:4730 4737

Bennetzen JL, Hall BD (1982) The primary structure of the Saccharomyces cerevisiae gene for alcohol dehydrogenase. J Biol Chem 257:3018-3025

Berner TS, Arneborg N (2012) The role of lager beer yeast in oxidative stability of model beer. Lett Appl Microbiol 54:225-232

Blasco L, Vinas M, Villa TG (2011) Proteins influencing foam formation in wine and beer: the role of yeast. Int Microbiol 14:61-71

Boer VM, Tai SL, Vuralhan Z, Arifin Y, Walsh MC, Piper MD, de Winde JH, Pronk JT, Daran JM (2007) Transcriptional responses of Saccharomyces cerevisiae to preferred and nonpreferred nitrogen sources in glucose-limited chemostat cultures. FEMS Yeast Res 7: 604-620

Bolat I, Romagnoli G, Zhu F, Pronk JT, Daran JM (2013) Functional analysis and transcriptional regulation of two orthologs of ARO10, encoding broad-substrate-specificity 2-oxo-acid decarboxylases, in the brewing yeast Saccharomyces pastorianus CBS1483. FEMS Yeast Res 13:505-517

Branyik T, Silva DP, Baszczynski M, Lehnert R, Silva J (2012) A review of methods of low alcohol and alcohol-free beer production. J Food Eng 108:493-506

Bravi E, Perretti G, Buzzini P, Della Sera R, Fantozzi P (2009) Technological steps and yeast biomass as factors affecting the lipid content of beer during the brewing process. J Agric Food Chem 57: $6279-6284$

Buhligen F, Rudinger P, Fetzer I, Stahl F, Scheper T, Harms H, Muller S (2013) Sustainability of industrial yeast serial repitching practice 
studied by gene expression and correlation analysis. J Biotechnol 168:718-728

Calderbank J, Hammond JRM (1994) Influence of higher alcohol availability on ester formation by yeast. J Am Soc Brew Chem 52:84-90

Chen E-H (1978) Relative contribution of Ehrlich and biosynthetic pathways to the formation of fusel alcohols. J Am Soc Brew Chem 36: $39-43$

Cooper TG (2002) Transmitting the signal of excess nitrogen in Saccharomyces cerevisiae from the Tor proteins to the GATA factors: connecting the dots. FEMS Microbiol Rev 26:223-238

Dekoninck T, Verbelen PJ, Delvaux F, Van Mulders SE, Delvaux F (2012) The importance of wort composition for yeast metabolism during accelerated brewery fermentations. J Am Soc Brew Chem 70:195-204

Dickinson JR, Norte V (1993) A study of branched-chain amino acid aminotransferase and isolation of mutations affecting the catabolism of branched-chain amino acids in Saccharomyces cerevisiae. FEBS Lett 326:29-32

Dickinson JR, Lanterman MM, Danner DJ, Pearson BM, Sanz P, Harrison SJ, Hewlins MJ (1997) A ${ }^{13} \mathrm{C}$ nuclear magnetic resonance investigation of the metabolism of leucine to isoamyl alcohol in Saccharomyces cerevisiae. J Biol Chem 272:26871-26878

Dickinson JR, Harrison SJ, Hewlins MJ (1998) An investigation of the metabolism of valine to isobutyl alcohol in Saccharomyces cerevisiae. J Biol Chem 273:25751-25756

Dickinson JR, Harrison SJ, Dickinson JA, Hewlins MJ (2000) An investigation of the metabolism of isoleucine to active amyl alcohol in Saccharomyces cerevisiae. J Biol Chem 275:10937-10942

Dickinson JR, Salgado LE, Hewlins MJ (2003) The catabolism of amino acids to long chain and complex alcohols in Saccharomyces cerevisiae. J Biol Chem 278:8028-8034

Didion T, Grauslund M, Kielland-Brandt MC, Andersen HA (1996) Amino acids induce expression of BAP2, a branched-chain amino acid permease gene in Saccharomyces cerevisiae. J Bacteriol 178: 2025-2029

Dufour JP (1994) Higher alcohols, acids and ester secretion during yeast growth. In: Proceedings of the 6th Jean De Clerck Chair. Academic, Leuven, pp 1-40

Eden A, Simchen G, Benvenisty N (1996) Two yeast homologs of ECA39, a target for c-Myc regulation, code for cytosolic and mitochondrial branched-chain amino acid aminotransferases. J Biol Chem 271:20242-20245

Eden A, Van Nedervelde L, Drukker M, Benvenisty N, Debourg A (2001) Involvement of branched-chain amino acid aminotransferases in the production of fusel alcohols during fermentation in yeast. Appl Microbiol Biotechnol 55:296-300

Ehrlich F (1907) Über die Bedingungen der Fuselölbildung und über ihren Zusammenhang mit dem Eiweissaufbau der Hefe. Ber Dtsch Chem Ges 40:1027-1047

Engan S (1970) Wort composition and beer flavour I: the influence of some amino acids on the formation of higher aliphatic alcohols and esters. J Inst Brew 76:254-261

Engan S (1974) Esters in beer. J Inst Brew Dig 49:40-48

Engan S (1981) Beer composition: volatile substances. In: Pollock JRA (ed) Brewing science, vol 2. Academic, London, pp 93-165

Engan S and Aubert O (1977) Relations between fermentation temperature and the formation of some flavour components. In: 16th European brewery convention congress, pp 591-607, Netherlands, Amsterdam

Fujii T, Nagasawa N, Iwamatsu A, Bogaki T, Tamai Y, Hamachi M (1994) Molecular cloning, sequence analysis, and expression of the yeast alcohol acetyltransferase gene. Appl Environ Microbiol 60:2786-2792

Fujii T, Yoshimoto H, Nagasawa N, Bogaki T, Tamai Y, Hamachi M (1996) Nucleotide sequences of alcohol acetyltransferase genes from lager brewing yeast, Saccharomyces carlsbergensis. Yeast 12:593-598

Fujii T, Kobayashi O, Yoshimoto H, Furukawa S, Tamai Y (1997) Effect of aeration and unsaturated fatty acids on expression of the Saccharomyces cerevisiae alcohol acetyltransferase gene. Appl Environ Microbiol 63:910-915

Fujiwara D, Yoshimoto H, Sone H, Harashima S, Tamai Y (1998) Transcriptional co-regulation of Saccharomyces cerevisiae alcohol acetyltransferase gene, ATF1 and delta-9 fatty acid desaturase gene, OLE1 by unsaturated fatty acids. Yeast 14:711-721

Fujiwara D, Kobayashi O, Yoshimoto H, Harashima S, Tamai Y (1999) Molecular mechanism of the multiple regulation of the Saccharomyces cerevisiae ATF1 gene encoding alcohol acetyltransferase. Yeast 15:1183-1197

Fukuda K, Kuwahata O, Kiyokawa Y, Yanagiuchi T, Wakai Y, Kitamoto K, Inoue Y, Kimura A (1996) Molecular cloning and nucleotide sequence of the isoamyl acetate-hydrolyzing esterase gene (EST2) from Saccharomyces cerevisiae. J Ferment Bioeng 82:8-15

Fukuda K, Yamamoto N, Kiyokawa Y, Yanagiuchi T, Wakai Y, Kitamoto K, Inoue Y, Kimura A (1998a) Balance of activities of alcohol acetyltransferase and esterase in Saccharomyces cerevisiae is important for production of isoamyl acetate. Appl Environ Microbiol 64: 4076-4078

Fukuda K, Yamamoto N, Kiyokawa Y, Yanagiuchi T, Wakai Y, Kitamoto K, Inoue Y, Kimura A (1998b) Brewing properties of sake yeast whose EST2 gene encoding isoamyl acetate-hydrolyzing esterase was disrupted. J Ferment Bioeng 85:101-106

Gibson BR, Lawrence SJ, Boulton CA, Box WG, Graham NS, Linforth RS, Smart KA (2008) The oxidative stress response of a lager brewing yeast strain during industrial propagation and fermentation. FEMS Yeast Res 8:574-585

Hiralal L, Olaniran AO, Pillay B (2013) Aroma-active ester profile of ale beer produced under different fermentation and nutritional conditions. J Biosci Bioeng 117:57-64

Hofman-Bang J (1999) Nitrogen catabolite repression in Saccharomyces cerevisiae. Mol Biotechnol 12:35-73

Hull G (2008) Olive oil addition to yeast as an alternative to wort aeration. Technol Q Master Brew Assoc Am 45:17-23

Iraqui I, Vissers S, Andre B, Urrestarazu A (1999) Transcriptional induction by aromatic amino acids in Saccharomyces cerevisiae. Mol Cell Biol 19:3360-3371

Jenkins CL, Kennedy AI, Hodgson JA, Pa T, Smart KA (2003) Impact of serial repitching on lager brewing yeast quality. J Am Soc Brew Chem 61:1-9

Kispal G, Steiner H, Court DA, Rolinski B, Lill R (1996) Mitochondrial and cytosolic branched-chain amino acid transaminases from yeast, homologs of the myc oncogene-regulated Eca39 protein. J Biol Chem 271:24458-24464

Knatchbull FB, Slaughter JC (1987) The effect of low $\mathrm{CO}_{2}$ pressure on the absorption of amino acids and production of flavour-active volatiles by yeast. J Inst Brew 93:420-424

Kohlhaw GB (2003) Leucine biosynthesis in fungi: entering metabolism through the back door. Microbiol Mol Biol Rev 67:1-15, table of contents

Krogerus K, Gibson BR (2013) Diacetyl and its control during brewery fermentation. J Inst Brew 119:86-97

Landaud S, Latrille E, Corrieu G (2001) Top pressure and temperature control the fusel alcohol/ester ratio through yeast growth in beer fermentation. J Inst Brew 107:107-117

Lee K, Hahn JS (2013) Interplay of Aro80 and GATA activators in regulation of genes for catabolism of aromatic amino acids in Saccharomyces cerevisiae. Mol Microbiol 88:1120-1134

Lee K, Sung C, Kim BG, Hahn JS (2013) Activation of Aro80 transcription factor by heat-induced aromatic amino acid influx in Saccharomyces cerevisiae. Biochem Biophys Res Commun 438:43-47 
Lei H, Zhao H, Yu Z, Zhao M (2012) Effects of wort gravity and nitrogen level on fermentation performance of brewer's yeast and the formation of flavor volatiles. Appl Biochem Biotechnol 166:1562-1574

Lei H, Li H, Mo F, Zheng L, Zhao H, Zhao M (2013a) Effects of Lys and His supplementations on the regulation of nitrogen metabolism in lager yeast. Appl Microbiol Biotechnol 97:8913-8921

Lei H, Zhao H, Zhao M (2013b) Proteases supplementation to high gravity worts enhances fermentation performance of brewer's yeast. Biochem Eng J 77:1-6

Lei H, Zheng L, Wang C, Zhao H, Zhao M (2013c) Effects of worts treated with proteases on the assimilation of free amino acids and fermentation performance of lager yeast. Int J Food Microbiol 161: $76-83$

Libkind D, Hittinger CT, Valerio E, Goncalves C, Dover J, Johnston M, Goncalves P, Sampaio JP (2011) Microbe domestication and the identification of the wild genetic stock of lager-brewing yeast. Proc Natl Acad Sci U S A 108:14539-14544

Lilly M, Bauer FF, Lambrechts MG, Swiegers JH, Cozzolino D, Pretorius IS (2006) The effect of increased yeast alcohol acetyltransferase and esterase activity on the flavour profiles of wine and distillates. Yeast 23:641-659

Lodolo EJ, Kock JL, Axcell BC, Brooks M (2008) The yeast Saccharomyces cerevisiae - the main character in beer brewing. FEMS Yeast Res 8:1018-1036

Ma J, Lu Q, Yuan Y, Ge H, Li K, Zhao W, Gao Y, Niu L, Teng M (2011) Crystal structure of isoamyl acetate-hydrolyzing esterase from Saccharomyces cerevisiae reveals a novel active site architecture and the basis of substrate specificity. Proteins 79:662-668

Malcorps P, Dufour JP (1992) Short-chain and medium-chain aliphaticester synthesis in Saccharomyces cerevisiae. Eur J Biochem 210: 1015-1022

Malcorps P, Cheval JM, Jamil S, Dufour J-P (1991) A new model for the regulation of ester synthesis by alcohol acetyltransferase in Saccharomyces cerevisiae. J Am Soc Brew Chem 49:47-53

Mason AB, Dufour JP (2000) Alcohol acetyltransferases and the significance of ester synthesis in yeast. Yeast 16:1287-1298

Meilgaard MC (1975a) Flavor chemistry of beer: part I: flavor interaction between principal volatiles. MBAA. Technol Q 12:107-117

Meilgaard MC (1975b) Flavour chemistry of beer. Part II: flavor and threshold of 239 aroma volatiles. MBAA. Technol Q 12:151-168

Meilgaard MC (1991) The flavor of beer. MBAA Technol Q 28:132-141

Mojzita D, Hohmann S (2006) Pdc2 coordinates expression of the THI regulon in the yeast Saccharomyces cerevisiae. Mol Genet Genomics 276:147-161

Molina AM, Swiegers JH, Varela C, Pretorius IS, Agosin E (2007) Influence of wine fermentation temperature on the synthesis of yeast-derived volatile aroma compounds. Appl Microbiol Biotechnol 77:675-687

Montanari L, Marconi O, Mayer H, Fantozzi P (2009) Production of alcohol-free beer. In: Beer in health and disease prevention. Elsevier, Burlington, pp 61-75

Moonjai N, Verstrepen KJ, Delvaux FR, Derdelinckx G, Verachtert H (2002) The effects if linoleic acid supplementation of cropped yeast on its subsequent fermentation performance and acetate ester synthesis. J Inst Brew 108:227-235

Nagasawa N, Bogaki T, Iwamatsu A, Hamachi M, Kumagai C (1998) Cloning and nucleotide sequence of the alcohol acetyltransferase II gene (ATF2) from Saccharomyces cerevisiae Kyokai No. 7. Biosci Biotechnol Biochem 62:1852-1857

Neubauer O, Fromherz K (1911) Über den Abbau der Aminosäuren bei der Hefegärung. Hoppe-Seyler's Z. Physiol Chem 70:326-350

Neven H, Delvaux F, Derdelinckx G (1997) Flavor evolution of top fermented beers. MBAA Technol Q 34:115-118

Nordström K (1962) Formation of ethyl acetate in fermentation with brewer's yeast III. Participation of coenzyme A. J Inst Brew 68: 398-407
Nykanen L, Nykanen I (1977) Production of esters by different yeast strains in sugar fermentations. J Inst Brew 83:30-31

Nykanen I, Suomalainen H (1983) Formation of aroma compounds by yeast. In: Nyaken I, Suomalainen H (eds) Aroma of beer, wine and distilled beverages. Reidel, Dordrecht, pp 3-16

Nykiinen L, Nykiinen I, Suomalainen H (1977) Distribution of esters produced during sugar fermentation between the yeast cell and the medium. J Inst Brew 83:32-34

Oshita K, Kubota M, Uchida Ma, and Ono M (1995) Clarification of the relationship between fusel alcohol formation and amino acid assimilation by brewing yeast using ${ }^{13} \mathrm{C}$-labeled amino acid. In: 25 th European brewery convention congress, pp 387-402, Brussels

Peddie HAB (1990) Ester formation in brewery fermentations. J Inst Brew Dig 96:327-331

Perpete P, Collin S (2000) Influence of beer ethanol content on the wort flavour perception. Food Chem 71:379-385

Picotti P, Clement-Ziza M, Lam H, Campbell DS, Schmidt A, Deutsch EW, Rost H, Sun Z, Rinner O, Reiter L, Shen Q, Michaelson JJ, Frei A, Alberti S, Kusebauch U, Wollscheid B, Moritz RL, Beyer A, Aebersold R (2013) A complete mass-spectrometric map of the yeast proteome applied to quantitative trait analysis. Nature 494: 266-270

Piddocke MP, Kreisz S, Heldt-Hansen HP, Nielsen KF, Olsson L (2009) Physiological characterization of brewer's yeast in high-gravity beer fermentations with glucose or maltose syrups as adjuncts. Appl Microbiol Biotechnol 84:453-464

Powell CD, Diacetis AN (2007) Long term serial repitching and the genetic and phenotypic stability of brewer's yeast. J Inst Brew 113:67-74

Procopio S, Krausea D, Hofmannb T, Beckera T (2013) Significant amino acids in aroma compound profiling during yeast fermentation analyzed by PLS regression. LWT Food Sci Technol 51:423-432

Ramos-Jeunehomme C, Laub R, Masschelein CA (1991) Why is ester formation in brewery fermentations yeast strain dependent? In: 23rd European brewery convention congress. Oxford University, Lisbon, pp 257-264

Renger RS, Van Hateren SH, Luyben KCAM (1992) The formation of esters and higher alcohols during brewery fermentation - the effect of carbon dioxide pressure. J Inst Brew 98:509-513

Rice JF, Chicoye E, Helbert JR (1977) Inhibition ofbeer volatiles formation by carbon dioxide pressure. J Am Soc Brew Chem 35:35-40

Rodrigues JA, Barros AS, Carvalho B, Brandao T, Gil AM (2011) Probing beer aging chemistry by nuclear magnetic resonance and multivariate analysis. Anal Chim Acta 702:178-187

Romagnoli G, Luttik MA, Kotter P, Pronk JT, Daran JM (2012) Substrate specificity of thiamine pyrophosphate-dependent 2-oxo-acid decarboxylases in Saccharomyces cerevisiae. Appl Environ Microbiol 78:7538-7548

Rossouw D, Naes T, Bauer FF (2008) Linking gene regulation and the exo-metabolome: a comparative transcriptomics approach to identify genes that impact on the production of volatile aroma compounds in yeast. BMC Genomics 9:530

Russell DW, Smith M, Williamson VM, Young ET (1983) Nucleotide sequence of the yeast alcohol dehydrogenase II gene. J Biol Chem 258:2674-2682

Saerens SM, Verstrepen KJ, Van Laere SD, Voet AR, Van Dijck P, Delvaux FR, Thevelein JM (2006) The Saccharomyces cerevisiae EHT1 and EEB1 genes encode novel enzymes with medium-chain fatty acid ethyl ester synthesis and hydrolysis capacity. J Biol Chem 281:4446-4456

Saerens SM, Delvaux F, Verstrepen KJ, Van Dijck P, Thevelein JM, Delvaux FR (2008a) Parameters affecting ethyl ester production by Saccharomyces cerevisiae during fermentation. Appl Environ Microbiol 74:454-461

Saerens SM, Verbelen PJ, Vanbeneden N, Thevelein JM, Delvaux FR (2008b) Monitoring the influence of high-gravity brewing and 
fermentation temperature on flavour formation by analysis of gene expression levels in brewing yeast. Appl Microbiol Biotechnol 80: 1039-1051

Saison D, De Schutter DP, Uyttenhove B, Delvaux F, Delvaux FR (2009) Contribution of staling compounds to the aged flavour of lager beer by studying their flavour thresholds. Food Chem 114:1206-1215

Sato M, Watari J, Ha S, Koshino S (1994) Instability in electrophoretic karyotype of brewing yeasts. J Am Soc Brew Chem 52:148-151

Schoondermark-Stolk SA, Tabernero M, Chapman J, Ter Schure EG, Verrips CT, Verkleij AJ, Boonstra J (2005) Bat2p is essential in Saccharomyces cerevisiae for fusel alcohol production on the nonfermentable carbon source ethanol. FEMS Yeast Res 5:757-766

Sentheshanmuganathan S, Elsden SR (1958) The mechanism of the formation of tyrosol by Saccharomyces cerevisiae. Biochem J 69: 210-218

Sentheshanuganathan S (1960) The mechanism of the formation of higher alcohols from amino acids by Saccharomyces cerevisiae. Biochem J 74:568-576

Shanta Kumara HMC, Fukui N, Kojima K, Nakatani K (1995) Regulation mechanism of ester formation by dissolved carbon dioxide during beer fermentation. MBAA Technol Q 32:159-162

Shindo S, Murakani J, Koshino S (1992) Control of acetate ester formation during alcohol fermentation with immobilized yeast. J Ferment Bioeng 73:370-374

Stewart G (2007) High gravity brewing- the pros and cons. New Food 1: $42-46$

Strejc J, Siříštová L, Karabín M, Silva J, Brányik T (2013) Production of alcohol-free beer with elevated amounts of flavouring compounds using lager yeast mutants. J Inst Brew 119:149-155

Suomalainen H (1981) Yeast esterases and aroma esters in alcoholic beverages. J Inst Brew 87:296-300

Taylor GT, Tburston PA, Kirsop BH (1979) lnfluence of lipids derived from malt spent grains on yeast metabolism and fermentation. J Inst Brew 85:219-227

Thurston PA, Quain DE, Tuhh RS (1982) Lipid metabolism and the regulation of volatile synthesis in Saccharomyces cerevisiae. J Inst Brew 88:90-94

Urrestarazu A, Vissers S, Iraqui I, Grenson M (1998) Phenylalanine- and tyrosine-auxotrophic mutants of Saccharomyces cerevisiae impaired in transamination. Mol Gen Genet 257:230-237

Vanderhaegen B, Neven H, Coghe S, Verstrepen KJ, Derdelinckx G, Verachtert H (2003) Bioflavoring and beer refermentation. Appl Microbiol Biotechnol 62:140-150

Vanderhaegen B, Neven H, Verachtert H, Derdelinckx G (2006) The chemistry of beer aging — a critical review. Food Chem 95:357-381

Vasconcelles MJ, Jiang Y, McDaid K, Gilooly L, Wretzel S, Porter DL, Martin CE, Goldberg MA (2001) Identification and characterization of a low oxygen response element involved in the hypoxic induction of a family of Saccharomyces cerevisiae genes. Implications for the conservation of oxygen sensing in eukaryotes. J Biol Chem 276: 14374-14384

Vaughan MA, Kurtzman CP (1985) Deoxyribonucleic acid relatedness among species of the genus Saccharomyces sensu stricto. Int J Syst Bacteriol 35:508-511

Verbelen PJ, Dekoninck TM, Saerens SM, Van Mulders SE, Thevelein JM, Delvaux FR (2009) Impact of pitching rate on yeast fermentation performance and beer flavour. Appl Microbiol Biotechnol 82:155-167

Verstrepen KJ, Derdelinckx G, Dufour JP, Winderickx J, Pretorius IS, Thevelein JM, Delvaux FR (2003a) The Saccharomyces cerevisiae alcohol acetyl transferase gene ATF1 is a target of the cAMP/PKA and FGM nutrient-signalling pathways. FEMS Yeast Res 4:285-296

Verstrepen KJ, Van Laere SD, Vanderhaegen BM, Derdelinckx G, Dufour JP, Pretorius IS, Winderickx J, Thevelein JM, Delvaux FR (2003b) Expression levels of the yeast alcohol acetyltransferase genes ATF1, Lg-ATF1, and ATF2 control the formation of a broad range of volatile esters. Appl Environ Microbiol 69:5228-5237

Vieira E, Brandao T, Ferreira IM (2013) Evaluation of brewer's spent yeast to produce flavor enhancer nucleotides: influence of serial repitching. J Agric Food Chem 61:8724-8729

Vuralhan Z, Morais MA, Tai SL, Piper MD, Pronk JT (2003) Identification and characterization of phenylpyruvate decarboxylase genes in Saccharomyces cerevisiae. Appl Environ Microbiol 69: $4534-4541$

Vuralhan Z, Luttik MA, Tai SL, Boer VM, Morais MA, Schipper D, Almering MJ, Kotter P, Dickinson JR, Daran JM, Pronk JT (2005) Physiological characterization of the ARO10-dependent, broadsubstrate-specificity 2-oxo acid decarboxylase activity of Saccharomyces cerevisiae. Appl Environ Microbiol 71:3276-3284

Williams RS, Wagner HP (1978) The isolation and identification of new staling related compounds form beer. J Am Soc Brew Chem 36:27-31

Williams RS, Wagner HP (1979) Contribution of hop bitter substances to beer staling mechanisms. J Am Soc Brew Chem 37:13-19

Yoshimoto H, Fujiwara D, Momma T, Ito C, Sone H, Kaneko Y, Tamai Y (1998) Characterization of the ATF1 and Lg-ATF1 genes encoding alcohol acetyltransferases in the bottom fermenting yeast Saccharomyces pastorianus. J Ferment Bioeng 86:15-20

Yoshioka K, Hashimoto N (1981) Ester formation by alcohol acetyltransferase from brewers yeast. Agric Biol Chem 45:2183-2190

Younis OS, Stewart GG (1998) Sugar uptake and subsequent ester and higher alcohol production by Saccharomyces cerevisiae. J Inst Brew 104:255-264

Younis OS, Stewart GG (1999) The effect of malt wort, very high gravity malt wart and very high gravity adjunct wort on volatile production in Saccharomyces cerevisiae. J Am Soc Brew Chem 57:39-45

Younis OS, Stewart GG (2000) The effect of wort maltose content on volatile production and fermentation performance in brewing yeast. In: Smart K (ed) Brewing yeast fermentation performance, 1st edn. Blackwell, Oxford, pp 170-176

Yu Z, Zhao H, Li H, Zhang Q, Lei H, Zhao M (2012) Selection of Saccharomyces pastorianus variants with improved fermentation performance under very high gravity wort conditions. Biotechnol Lett 34:365-370

Yukiko K, Fumihiko O, Keiji M, Toshihiko A (2001) Control of higher alcohol production by manipulation of the BAP2 gene in brewing yeast. J Am Soc Brew Chem 59:157-162

Zhang C, Liu Y, Qi Y, Zhang J, Dai L, Lin X, Xiao D (2013) Increased esters and decreased higher alcohols production by engineered brewer's yeast strains. Eur Food Res Technol 236:1009-1014 